\title{
GAIA Level 3 First Trimester Spontaneous Abortion
}

National Cancer Institute

\section{Source}

National Cancer Institute. GAIA Level 3 First Trimester Spontaneous Abortion. NCI

Thesaurus. Code C128778.

GAIA Level 3 First Trimester Spontaneous Abortion is defined by three criteria: first, it does not qualify as either a Level 1 or Level 2 First Trimester Spontaneous Abortion; second, gestational age is within the pre-defined range for the selected abortion definition as assessed by maternal and/or fetal parameters (Level 3) (using Brighton Preterm Birth Gestational Age algorithm); third, a positive urine or blood pregnancy test that becomes negative after 7 days. 